\title{
COMMUNICATIONS
}

Ecological Applications, 16(4), 2006, pp. 1311-1318

(C) 2006 by the the Ecological Society of America

\section{THE CHALLENGE OF PROVIDING ENVIRONMENTAL FLOW RULES TO SUSTAIN RIVER ECOSYSTEMS}

\author{
Angela H. Arthington, ${ }^{1,4}$ Stuart E. Bunn, ${ }^{1}$ N. LeRoy Poff, ${ }^{2}$ and Robert J. Naiman ${ }^{3}$ \\ ${ }^{1}$ Centre for Riverine Landscapes and eWater Cooperative Research Centre, Griffith University, Nathan, Queensland 4111 Australia \\ ${ }^{2}$ Department of Biology, Colorado State University, Fort Collins, Colorado 80523-1878 USA \\ ${ }^{3}$ School of Aquatic and Fishery Sciences, Box 355020, University of Washington, Seattle, Washington 98195 USA
}

\begin{abstract}
Accounting for natural differences in flow variability among rivers, and understanding the importance of this for the protection of freshwater biodiversity and maintenance of goods and services that rivers provide, is a great challenge for water managers and scientists. Nevertheless, despite considerable progress in understanding how flow variability sustains river ecosystems, there is a growing temptation to ignore natural system complexity in favor of simplistic, static, environmental flow "rules" to resolve pressing river management issues. We argue that such approaches are misguided and will ultimately contribute to further degradation of river ecosystems. In the absence of detailed empirical information of environmental flow requirements for rivers, we propose a generic approach that incorporates essential aspects of natural flow variability shared across particular classes of rivers that can be validated with empirical biological data and other information in a calibration process. We argue that this approach can bridge the gap between simple hydrological "rules of thumb" and more comprehensive environmental flow assessments and experimental flow restoration projects.
\end{abstract}

Key words: benchmarking; classification; flow-ecological relationships; flow variability; natural flow regime paradigm; river ecosystem condition.

\section{INTRODUCTION}

The common etymology of the words "river" and "rivalry" from the Latin rivalis (pertaining to streams or rivers) is evidence of the age-long conflict over shared resources between humans living on opposite banks of rivers. These conflicts continue today but have become more complicated as society has grown to appreciate that rivers also require ample water to maintain essential ecosystem goods and services. Conflicts over freshwater resources are increasing as the global population rapidly rises (Rosenberg et al. 2000, Baron et al. 2002, Gleick et al. 2004). Compounding matters, global climate change presents new uncertainties about the variability of river flows, potentially leading to increased water-engineering responses and escalating ecosystem stress (McCarthy et al. 2001, Malmqvist and Rundle 2002).

There is now broad acceptance that it is in society's best interests to consider rivers (and other freshwater systems) as legitimate "users" of fresh water (Naiman et al. 2002, Postel and Richter 2003). However, the

Manuscript received 23 February 2006; accepted 6 March 2006. Corresponding Editor: J. S. Baron.

${ }^{4}$ E-mail: a.arthington@griffith.edu.au recognition that rivers and adjacent wetlands need adequate water of good quality to sustain ecological processes and associated goods and services is not new. Methods designed to quantify minimum "in-stream flows" to sustain fish appeared in the United States in the late 1940s. With increasing concern about the impact of dams and flow regulation on river biota, the scientific field of "environmental flows" prospered to produce more than 200 methods that can be grouped into four categories: hydrological rules, hydraulic rating methods, habitat simulation methods, and holistic methodologies (Dyson et al. 2003, Tharme 2003). In a surge of developments over the past decade or so, scientists now recognize that arbitrary "minimum" flows are inadequate - the structure and function of a riverine ecosystem and many adaptations of its biota are dictated by patterns of temporal variation in river flows (the "natural flow-regime paradigm"; Richter et al. 1996, Poff et al. 1997, Lytle and Poff 2004). There is now general agreement among scientists and many managers that to protect freshwater biodiversity and maintain the essential goods and services provided by rivers, we need to mimic components of natural flow variability, taking into consideration the magnitude, frequency, timing, duration, rate of change and predictability of flow events 
(e.g., floods and droughts), and the sequencing of such conditions.

The rapid acceptance of the natural flow regime concept has been accompanied by an expectation that ecologists can easily provide specific environmental flow prescriptions for riverine ecosystems. Unfortunately, translating general hydrologic-ecological principles and knowledge into specific management rules for particular river basins and reaches remains a daunting challenge (Poff et al. 2003). Governments, citizen groups and the private sector now seek answers to more specific questions: "How much can we change the flow regime of a river before the aquatic ecosystem begins to show decline; how should we manage the daily flows, floods and interannual patterns of variability to achieve desired ecological outcomes?" Scientific uncertainties associated with these and related questions can be addressed through carefully planned, long-term, adaptive flow management experiments (e.g., Grand Canyon flow release, [Rubin et al. 2002], Snowy River flow restoration program [Pigram 2000]). However, these experiments typically do not suit short management timeframes.

The reluctance or inability of ecologists to provide rapid or precise statements on specific ecological flow requirements for individual rivers often leads to tensions, indecision, and poor decisions (Arthington and Pusey 2003). In an effort to provide immediate advice on flows for river ecosystem protection, some scientists are returning to simple hydrological "rules of thumb" that purportedly associate degrees of flow modification with likely ecological outcomes. Recent proposals include those based on percentages of natural mean or median annual flow (e.g., the "one-third" proposal for Australian rivers [Cullen 2001]), percentages of total divertible annual flow allocated to wet and dry seasons (the Australian Land and Water Resources Audit; data available online), ${ }^{5}$ and environmental flow prescriptions for world rivers based on a percentage of total annual base flow plus a high flow component derived as a percentage of mean annual runoff (Smakhtin et al. 2004).

Such simplistic guides have no documented empirical basis and the temptation to adopt them represents a grave risk to the future integrity and biodiversity of the world's riverine ecosystems. For example, despite ample precautionary advice in applying the "two-thirds" target to rivers other than the Murray (Jones et al. 2001, Jones 2002), some water managers in Australia have, predictably, come to regard a third of a river's median annual flow as a legitimate target when allocating water for abstraction. Similarly, implementing the suggested flow targets to achieve "fair" ecological condition at 20-30\% MAR (mean annual runoff) for arid-zone regions with highly variable flow regimes, and up to $50 \%$ MAR for

\footnotetext{
${ }^{5}$ /http://audit.ea.gov.au/ANRA/water/docs/national/ Water_Contents.html $\rangle$
}

rivers in equatorial regions and some lake-regulated rivers (Smakhtin et al. 2004) would almost certainly cause profound ecological degradation, based on current scientific knowledge (Poff et al. 1997, Pusey et al. 2000, Bunn and Arthington 2002, Nilsson and Svedmark 2002, Petr et al. 2004). Indeed, such static rules defy fundamental understanding of the critical roles of flow variability in sustaining riverine ecosystems. Extracting a third to a half of a river's annual discharge (mean or median) would almost certainly alter the timing and range of variation of ecologically important flow events. Furthermore, in arid-zone streams and rivers with very high interannual variation in MAR, such levels of abstraction would lead to complete dewatering in years of low runoff and severe ecological impacts (Arthington et al. 2005, Hamilton et al. 2005, Bunn et al. 2006).

With growing recognition of the value of river ecosystem goods and services, and escalating global impacts of human development and climate change on aquatic systems (Postel and Richter 2003, Vörösmarty et al. 2004, Nilsson et al. 2005; Dudgeon et al. 2006), now is a critically important time for scientists, managers, and governments to agree on a scientifically defensible approach to setting environmental flows and to identify and avoid methods that pose an unacceptable level of risk of degradation. We propose an approach to the identification of environmental flow guidelines that bridges the gap between simple hydrological "rules of thumb" and more comprehensive, river-specific, environmental, flow assessments.

\section{Development of Regional Environmental Flow "STANDARDS"}

While we reject the notion that simple "rules of thumb" can guide responsible management of riverine ecosystems, we acknowledge the challenge (and frustration) of formulating flow prescriptions for rivers in the short term in the absence of site-specific ecological data. However, we emphasize that just because this cannot be done easily, there is no justification to revert to an overly simplistic approach, and we offer some suggestions for a possible path forward. In doing so, we also acknowledge our incomplete scientific understanding of how flow alteration interacts with other landscape-scale modifications, such as land use change, to degrade riverine ecosystems (Allan 2004). More sophisticated sampling designs are needed, using robust indicators that can diagnose cause-effect relationships, to separate the effects of flow modification per se from the effects of land use that often accompany major water resource developments (Bunn and Arthington 2002).

A "stop-gap" approach for developing scientifically defensible environmental flow guidelines needs to incorporate an essential appreciation of natural patterns of flow variability and a process for feasibly calibrating the flow standards with empirical biological data and other available information. Environmental flow guidelines or "standards" can be developed in two very 
different contexts, each having slightly different criteria for application (Poff et al. 2006). First, for specific river systems, the adaptive management process can be used to set flow targets based on natural flow variability, best available hydro-ecological knowledge and expert opinion that can be validated with monitoring to establish site-specific "benchmarks" for ecological condition or "health" targets (e.g., Arthington and Pusey 2003, Poff et al. 2003, Richter et al. 2003). This approach is most appropriate for specific rivers having either great scientific or societal interest (e.g., restoration projects) or for larger river systems that are arguably unique. It is being applied or is proposed for several rivers in the United States (Baron et al. 2002, Poff et al. 2003, Richter et al. 2003, 2006) and aims to achieve important ecological outcomes in Australia's River Murray (e.g., enhanced recruitment of waterbirds and riparian vegetation [Siebentritt et al. 2004, George et al. 2005]).

The second, and more general, context applies to most of the world's rivers and streams, for which site-specific biotic and hydrologic data neither exist nor will be forthcoming in the short term. There is a clear need to develop credible approaches to support flow management for these systems (Smakhtin et al. 2004, Bragg et al. 2005, Nilsson et al. 2005); however, this cannot be achieved in a timely fashion if site-specific information is required for every river. Therefore, we propose that, rather than attempting to manage for the "uniqueness" of every individual river's natural flow regime, we identify "classes" of streams based on key attributes of flow variability, and then calibrate relationships between alterations in each flow attribute and measures of ecological condition for each stream class. Indeed, the aquatic and riparian biota of a stream or river have not been shown to be uniquely adapted to the details of every individual river's flow regime (Lytle and Poff 2004), even though the literature does strongly support the generalization that different types of flow variability support different ecological communities and life history strategies (Poff and Ward 1989, Poff et al. 1997, Pusey et al. 2000, Biggs et al. 2005). Accordingly, classifying streams into ecologically meaningful groups allows the identification of practical management units, i.e., distinct stream classes for which there is a specific natural range of both hydrological and biotic variation. We propose that hydrological classification based on statistically meaningful numbers of gauged or modeled streams, combined with calibration of ecological condition across the distribution of natural and modified hydrologic values for each class of stream, is particularly suited for developing scientifically defensible environmental flow guidelines at regional or national scales, at which substantial variation in climatic, physiographic, and ecological conditions prevails. Within a region, the ecological characteristics of streams/rivers in each hydrological class are expected to be relatively similar compared to ecological characteristics between the classes; therefore, these classes represent distinct "man- agement units." There are four basic steps to this proposed approach (see also Fig. 1).

Step 1: Develop classification for reference streams.(Fig. 1a). Many ecologically based stream-flow classifications have been developed worldwide, including in the United States (Poff and Ward 1989, Poff 1996, Henriksen et al. 2006), Australia (Hughes and James 1989), and New Zealand (Snelder et al. 2005). All are based on a variety of descriptors of the natural flow regime (Olden and Poff 2003). The basic approach is to identify natural or "reference" streams in a region or obtain modeled premodified flow data and extract ecologically meaningful flow variables from the hydrograph that capture natural flow variability. There is much flexibility in choosing the appropriate flow variables, the metrics that represent them, the statistical method of classification, and the number of stream classes to be used for a given region. As a guide, the literature suggests that measures of flow magnitude (e.g., annual, seasonal, monthly, daily), the frequency, timing, duration and predictability of flow events (e.g., floods and droughts), rate of change from one flow condition to another (e.g., rate of rise and fall of flood hydrographs), and the temporal sequencing of flow conditions should be included as they influence many aspects of river ecosystems (Poff et al. 1997, Puckridge et al. 1998, Lytle and Poff 2004). Each class (e.g., classes A, B, and $\mathrm{C}$ in Fig. 1a) is defined by a particular weighting of a subset of the flow metrics used in the classification.

Step 2: Develop frequency distributions for each flow variable in each class.-(Fig. 1b). Each reference stream within a class will have a distribution of values for each defining flow variable/metric derived from the historic flow record. These distributions are likely to vary from one stream to another but when combined represent the natural range of spatial and temporal variation for all streams in the class. If some streams are un-gauged, statistical modeling can be used to estimate the flow metrics relevant to the regional classification by using nearby gauges in combination with drainage basin, climatic, and other types of landscape information (e.g., Snelder et al. 2005, Sanborn and Bledsoe 2005, Henriksen et al. 2006). In regions with sparse gauge density, water balance models may be used to provide coarser temporal resolution for simulated hydrographs (e.g., monthly or seasonal descriptors; Fekete et al. 2002) and these coarser-grained flow metrics can be related to high-resolution flow data from gauges (see Poff 1996).

Step 3: Compare frequency distributions from flowmodified streams with reference condition in the same class.-(Fig. 1c). Flow modification has to be defined in terms of deviation from the reference condition for each class of stream. First, each flow-impaired stream is assigned to one of the regional flow regime classes either by estimating the pre-disturbance flow metrics (see step 2) and making the assignment based on a statistical model, or based on landscape and climatic character-

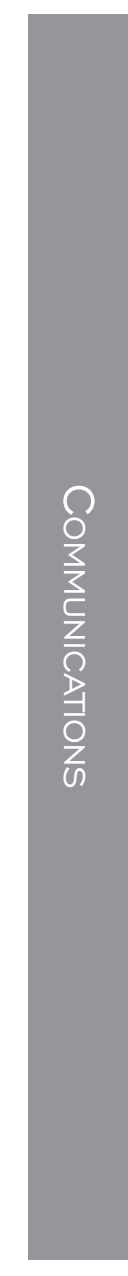




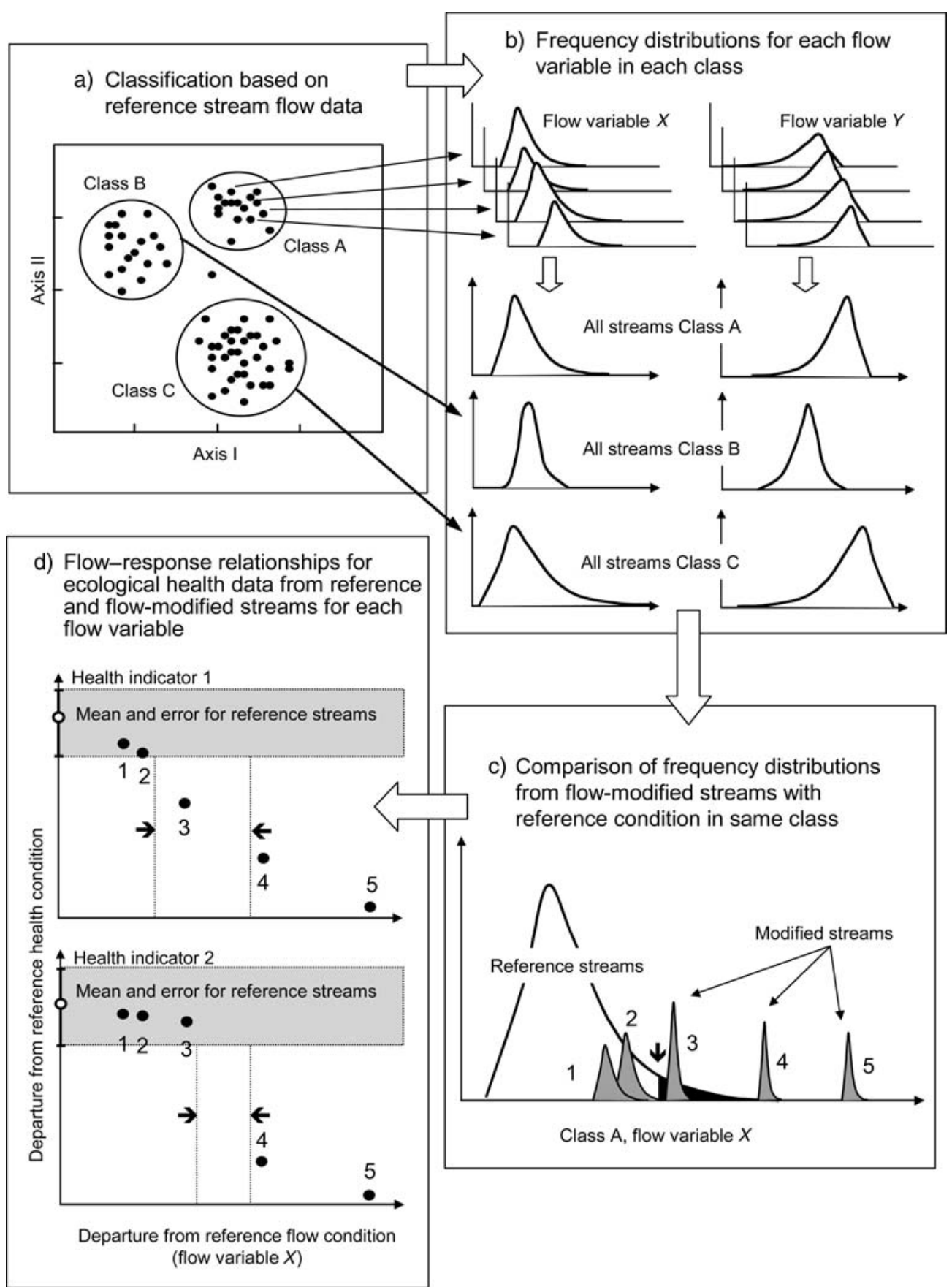

FIG. 1. (a) Reference streams are classified into hydrologically similar groups according to particular combinations of ecologically important flow variables extracted from the long-term hydrograph. (b) Frequency distributions are developed for each flow variable in each class and are combined to represent the natural range of spatial and temporal variation in each flow variable across all streams in the class. (c) Frequency distributions from flow-modified streams are compared with the reference condition frequency distribution for the particular stream class. (d) Flow-ecological response relationships are developed for each ecological health metric across the gradient of natural (or "reference") to modified flow regimes for each stream flow variable and stream class. Two critical "risk levels" or "benchmarks" (dotted vertical lines and arrows) are established to guide the setting of environmental flow standards.

istics. Then, for each flow-impaired stream, the degree of modification of any flow metric can be assessed with respect to the reference condition frequency distribution for that class. In the example provided (Fig. 1c, class A, flow variable $X$ ), streams 4 and 5 clearly lie outside of the natural range of variation for this variable and would be highly likely to show ecological impairment. Stream 3 falls beyond the 95th percentile of the natural 
range, and might also be expected to show some ecological impairment. Streams 1 and 2, on the other hand, show values that are well within the range of natural flow variation for this class and ecological impairment is unlikely. In the absence of ecological data or in circumstances where the collection of empirical ecological data is not possible, we suggest that the "benchmark" for high risk of ecological damage should be set at the 95th percentile of the reference frequency distribution for each defining flow variable, or at a lower level if the ecological assets of some streams within the particular class are considered to be of high value. This echoes the approach of the "indicators of hydrologic alteration" developed by Richter et al. (1996) and other methods that recommend flow "standards" based solely on hydrologic alteration (e.g., Black et al. 2005, Richter et al. 2006). However, we suggest it only as a precautionary principle to protect stream ecosystems when ecological validation cannot be achieved.

Step 4: Develop flow-response relationships for ecological health data from reference and flow modified steams for each flow variable.-(Fig. 1d). We believe it is imperative that ecological validation is a key feature of a robust approach. Accordingly, once the types and degrees of flow modification have been determined for representatives of a given class of streams, the final and critical step is to develop quantitative relationships between indicators of ecological condition (e.g., species richness, biomass, traits, assemblage structure, recruitment success) referenced to natural condition and degrees of flow modification. A representative sampling of flow-ecological relationships across the gradient of natural (or "reference") to impaired flow regimes for each stream class is needed. By comparing the ecological condition along a flow-impairment gradient, ecologically relevant flow standards can be developed and calibrated. It is possible to develop empirical flowresponse curves for each natural asset of interest (e.g., habitat, aquatic and riparian vegetation, invertebrates, fish, waterbirds) and each ecologically relevant flow variable defining the stream class (e.g., low flow discharge, the magnitude, timing and frequency of flood flows, duration of low flow spells, etc.). If necessary, expert judgment can contribute to the development of flow-response curves (see King et al. 2003, Arthington et al. 2004).

A key issue, of course, is the functional form of the flow-response relationship. This relationship may be linear (Fig. 1d, health indicator 1), such as the decrease in abundance or biomass of fish frequently documented months to years after a decrease in flood magnitude/area of floodplain inundated (Welcomme 2001). Alternatively, it may be a simple threshold response (Fig. 1d, health indicator 2), such as a marked decrease in wetted aquatic habitat with decreased channel flow, a typical result from the application of PHABSIM (Bovee 1982), or the failure of fish or colonially nesting waterbirds to breed if threshold water levels are not achieved (e.g.,
King et al. 1998, Kingsford and Auld 2005). For health indicator 1 in our example (Fig. 1d), stream 3 falls outside the range of values for reference streams 1 and 2 and is judged to be ecologically impaired, whereas for health indicator 2 , stream 3 is not impaired relative to reference condition for streams in that class. From these curves, two critical "risk levels" or "benchmarks" are established to guide the setting of environmental flow standards (dotted vertical lines and arrows in Fig. 1d). For each flow variable, risk level 1 establishes the limit that must be placed on flow modification if we wish to protect the natural assets of the stream or river, whereas risk level 2 represents the degree of flow alteration associated with severely degraded river conditions. Collectively, the individual flow-response curves and the two risk levels provide stakeholders and decision makers with significant information to guide the establishment of environmental flow standards for a particular class of stream. Conservative flow targets can be set such that the degree of flow modification does not exceed risk level 1 for all, or most, highly valued ecosystem attributes, or stakeholders may decide to accept a higher level of risk of ecological damage by allowing a particular hydrological variable to vary to a greater degree relative to the natural range for that stream class. We propose that the two risk levels can be regarded as the critical "benchmarks" to guide environmental flow allocations for each distinctive stream class: they define the best and worst case scenarios of ecological response to flow modification. This benchmarking process can be applied in two different management contexts: to evaluate the probable ecological consequences of a range of scenarios of flow modification for a particular stream within a class, or to establish guidelines for flow restoration in impaired streams of the same class. In Australia, benchmarking has become the standard method for setting limits to flow regime modification in Queensland's river basins (e.g., Fitzroy Basin Water Resource Plan, available online). ${ }^{6}$

\section{Advantages Relative to Other Methods}

The advantages of the proposed approach are that (1) it is "holistic" (sensu Tharme 2003, Arthington et al. 2004) as it addresses the flow requirements of many ecosystem components; (2) the method can be applied to assess the ecological consequences of change in each ecologically relevant flow variable that defines the stream class (Poff et al. 1997, Olden and Poff 2003); (3) empirically validated stress-response curves offer a scientifically defensible means to define two critical risk levels that are arguably the most important "benchmarks" needed to guide environmental flow allocations; (4) there is high probability that risk level 1 will protect the most sensitive species and ecological processes

\footnotetext{
${ }^{6}\langle$ http://www.nrm.qld.gov.au/wrp/fitzroy.html $\rangle$
} 


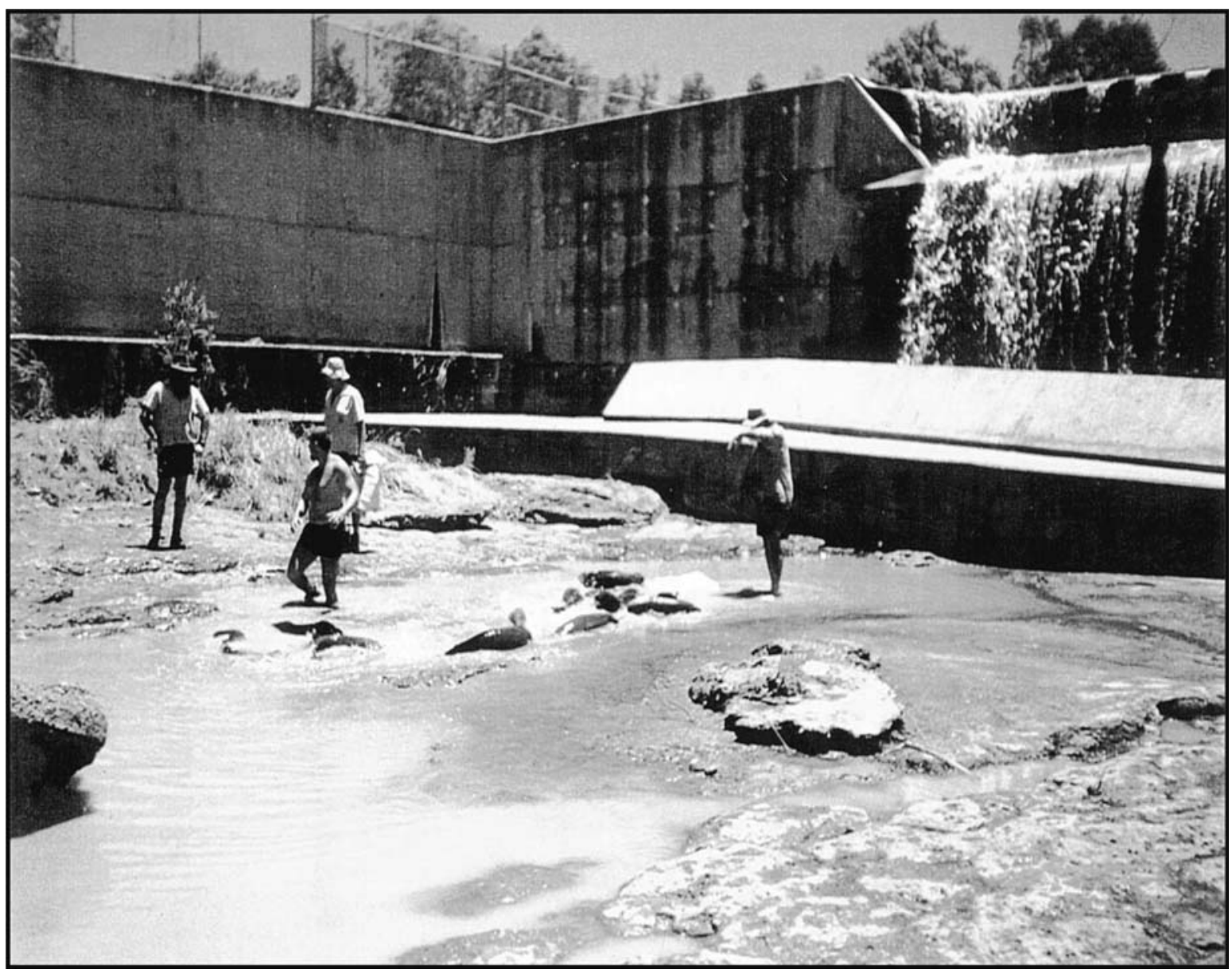

Plate 1. An example of loss of ecological goods provided by rivers: fish stranded below weir by rapid fall in water level. Photo credit: Chris Thompson.

dependent upon the timing and pattern of stream discharge, as well as serve as an "umbrella" flow target to protect species and processes as yet unstudied; (5) the method is intended for application to classes of streams that represent the substantial variation in climatic, physiographic, and ecological conditions prevailing at regional or national scales, and can therefore produce regional environmental flow guidelines.

One disadvantage of this approach is that it cannot be applied as effectively when most streams in a hydrologic class are un-impacted by human activities and there are few opportunities to calibrate ecological response to existing gradients of flow alteration. In such circumstances, it is feasible to employ methods such as DRIFT (Downstream Response to Imposed Flow Transformation; King et al. 2003) that rely substantially on expert knowledge to describe and rank, from low to high, the probable ecological consequences of proposed hydrologic alterations. Even though DRIFT is considered particularly useful where there are very few basic ecological data sets or limited understanding of hydrological-ecological relationships for a particular river
(King et al. 2003), the approach described herein is scientifically more defensible since it is founded upon validated stress-response relationships that indicate the risk of ecological damage if flows are altered in particular ways - and to particular degrees-within and between particular hydrologic stream classes (see Plate 1).

\section{Conclusions}

Implementation of scientifically credible, regional flow guidelines for the protection and restoration of the ecological integrity of streams and rivers will underpin a thoughtful, proactive, and positive management approach to maintaining sustainable river ecosystems. Even so, we regard the hydrologic classification and ecological calibration approach outlined above only as a near-term solution in the face of massive and widespread hydrologic alterations (Vörösmarty et al. 2004, Nilsson et al. 2005). It is an evolving approach that must be supported by long-term hydro-ecological research set within an adaptive management framework (Poff et al. 2003). Nevertheless, such an approach is needed to improve predictions of the ecological consequences of 
flow regulation and to inform the intensifying debates about ecosystem responses to flow modification and climate change (Baron et al. 2002, Naiman et al. 2002, Poff et al. 2003, Vörösmarty et al. 2004, Meyerson et al. 2005).

We suggest that a region-by-region and country-bycountry analysis using hydrological classification methods combined with ecological calibration could fairly rapidly provide global environmental flow guidelines within the coming decade. Considerable interest exists on a global scale to support such analyses; e.g., the International Association for Hydrological Sciences PUB initiative (described online), ${ }^{7}$ and the Global Water System Project (described online). ${ }^{8}$ The development of scientifically credible flow management guidelines in distinctive physiographic and ecological regions of the world would make a major contribution to the resolution of conflicts over shared water resources, and thereby help to ensure that societies continue to benefit from the biodiversity and essential ecological goods and services provided by river ecosystems.

\section{ACKNOWLEDGMENTS}

This communication is a product of our contributions to the Global Water System Project, DIVERSITAS, and the Global River Sustainability Project. Manuscript preparation benefited from a Land and Water Australia Fellowship (GRU 32 to A. H. Arthington and S. E. Bunn), a National Science Foundation (USA) award (NSF 04-37961 to N. L. Poff) and travel funds provided by the Centre for Riverine Landscapes, Griffith University. Two anonymous referees made insightful comments on an earlier version. We particularly thank Brian Richter of The Nature Conservancy, USA, and many colleagues who have shared their thoughts on the challenges of defining environmental flows to sustain riverine ecosystems.

\section{Literature Cited}

Allan, J. D. 2004. Landscapes and rivers: the influence of land use on stream ecosystems. Annual Review of Ecology, Evolution, and Systematics 35:257-284.

Arthington, A. H., S. R. Balcombe, G. A. Wilson, M. C. Thoms, and J. C. Marshall. 2005. Spatial and temporal variation in fish assemblage structure in isolated waterholes during the 2001 dry season of an arid-zone river, Cooper Creek, Australia. Marine and Freshwater Research 56:25-35.

Arthington, A. H., and B. J. Pusey. 2003. Flow restoration and protection in Australian rivers. River Research and Applications 19:377-395.

Arthington, A. H., R. S. Tharme, S. O. Brizga, B. J. Pusey, and M. J. Kennard. 2004. Environmental flow assessment with emphasis on holistic methodologies. Pages 37-65 in R. Welcomme and T. Petr', editors. Proceedings of the Second International Symposium on the Management of Large Rivers for Fisheries Volume II. RAP Publication 2004/17. FAO Regional Office for Asia and the Pacific, Bangkok, Thailand.

Baron, J. S., N. L. Poff, P. L. Angermeier, C. N. Dahm, P. H. Gleick, N. G. Hairston, Jr., R. B. Jackson, C. A. Johnston, B. D. Richter, and A. D. Steinman. 2002. Meeting ecological and societal needs for freshwater. Ecological Applications 12: $1247-1260$.

\footnotetext{
${ }^{7}\langle$ http://cee.uiuc.edu/research/pub/default.asp $\rangle$

${ }^{8}\langle$ http://www.gwsp.org/〉
}

Biggs, B. J. F., V. I. Nikora, and T. H. Snelder. 2005. Linking scales of flow variability to lotic ecosystem structure and function. River Research and Applications 21:283-298.

Black, A. R., J. S. Rowan, R. W. Duck, O. M. Bragg, and B. E. Clelland. 2005. DHRAM: a method for classifying river flow regime alterations for the EC Water Framework Directive. Aquatic Conservation: Marine and Freshwater Ecosystems 15:427-446.

Bovee, K. D. 1982. A guide to stream habitat analysis using the instream flow incremental methodology. Instream Flow Information Paper 12. FWS/OBS-82/26. U.S. Department of Fisheries and Wildlife Services, Washington, D.C., USA.

Bragg, D. M., A. R. Black, R. W. Duck, and J. S. Rowan. 2005. Approaching the physical-biological interface in rivers: a review of methods for ecological evaluation of flow regimes. Progress in Physical Geography 29:506-531.

Bunn, S. E., and A. H. Arthington. 2002. Basic principles and ecological consequences of altered flow regimes for aquatic biodiversity. Environmental Management 30:492-507.

Bunn, S. E., M. C. Thoms, S. K. Hamilton, and S. J. Capon. 2006. Flow variability in dryland rivers: boom, bust and the bits in between. River Research and Applications 22:179186.

Cullen P. 2001. The future of flow restoration in Australia. WaterShed September:1-2.

Dudgeon, D., A. H. Arthington, M. O. Gessner, Z. Kawabata, D. Knowler, C. Lévêque, R. J. Naiman, A.H. PrieurRichard, D. Soto, and M. L. J. Stiassny. 2006. Freshwater biodiversity: importance, threats, status, and conservation challenges. Biological Reviews 81(2):163-182.

Dyson, M., G. Berkamp, , and J. Scanlon, Editors. 2003. Flow: the essentials of environmental flows. IUCN, Gland, Switzerland and Cambridge, UK.

Fekete, B. M., C. J. Vörösmarty, and W. Grabs. 2002. High resolution fields of global runoff combining observed river discharge and simulated water balances. Global Biogeochemical Cycles, 16(3):Article no. 1042.

George, A. K., K. F. Walker, and M. M. Lewis. 2005. Population status of eucalypt trees on the River Murray floodplain, South Australia. River Research and Applications 21:271-282.

Gleick, P. H., N. L. Cain, D. Haasz, C. Henges-Jeck, C. Hunt, M. Kiparsky, M. Moench, M. Palaniappan, V. Srinivasan, and G. Wolff. 2004. The world's water 2004-2005: the biennial report on freshwater resources. Island Press, Washington, D.C., USA.

Hamilton, S. K., S. E. Bunn, M. C. Thoms, and J. C. Marshall. 2005. Persistence of aquatic refugia between flow pulses in a dryland river system (Cooper Creek, Australia). Limnology and Oceanography 50:743-754.

Henriksen, J. A., J. Heasley, J. G. Kennen, and S. Niewsand. 2006. Users' manual for the hydroecological integrity assessment process software: U.S. Geological Survery, Biological Resources Discipline, Open File Report 2006-1093. U.S. Geological Survey, Fort Collins, Colorado, USA.

Hughes, J. M. R., and B. James. 1989. A hydrological regionalisation of streams in Victoria, Australia, with implications for stream ecology. Australian Journal of Marine and Freshwater Research 40:303-326.

Jones, G. 2002. Setting environmental flows to sustain a healthy working river. Watershed, February 2002, pp. 1-2.

Jones, G., T. Hillman, R. Kingsford, T. McMahon, K. Walker, A. Arthington, J. Whittington, and S. Cartwright. 2001. Independent report of the Expert Reference Panel on environmental flows and water quality requirements for the River Murray system. Report to the Murray-Darling Ministerial Council. Cooperative Research Centre for Freshwater Ecology, Canberra, Australia.

King, J. M., C. A. Brown, and H. Sabet. 2003. A scenario-based holistic approach to environmental flow assessments for rivers. River Research and Applications 19:619-640. 
King, J. M., J. A. Cambray, and D. N. Impson. 1998. Linked effects of dam-released floods and water temperature on spawning of the Clanwilliam yellowfish Barbus capensis. Hydrobiologia 384:245-265.

Kingsford, R. T., and K. M. Auld. 2005. Waterbird breeding and environmental flow management in the Macquarie Marshes, arid Australia. River Research and Applications 2:187-200.

Lytle, D. H., and N. L. Poff. 2004. Adaptation to natural flow regimes. Trends in Ecology and Evolution 19:94-100.

Malmqvist, B., and S. Rundle. 2002. Threats to the running water ecosystems of the world. Environmental Conservation 29:134-153.

McCarthy, J. J., O. F. Canziani, N. A. Leary, D. J. Dokken, and K.S. White, editors. 2001. Climate change 2001: impacts, adaptation and vulnerability. Contribution of Working Group II to the Third Assessment Report of the Intergovernmental Panel on Climate Change (IPCC). Cambridge University Press, Cambridge, UK.

Meyerson, L. A., J. Baron, J. Melillo, R. J. Naiman, R. I. O'Malley, G. Orians, M. A. Palmer, A. S. P. Pfaff, S. W. Running, and O. E. Sala. 2005. Aggregate measures of ecosystem services: Can we take the pulse of nature? Frontiers in Ecology and the Environment 3:56-59.

Naiman, R. J., S. E. Bunn, C. Nilsson, G. E. Petts, G. Pinay, and L. C. Thompson. 2002. Legitimizing fluvial ecosystems as users of water: an overview. Environmental Management 30:455-467.

Nilsson, C., C. A. Reidy, M. Dynesius, and C. Revenga. 2005. Regulation of the world's large river systems. Science $\mathbf{3 0 8}$ : 405-408.

Nilsson, C., and M. Svedmark. 2002. Basic principles and ecological consequences of changing water regimes: riparian plant communities. Environmental Management 30:468-480.

Olden, J. D., and N. L. Poff. 2003. Redundancy and the choice of hydrologic indices for characterizing streamflow regimes. River Research and Applications 19:101-121.

Petr, T., K. Ismukhanov, B. Kamilov, D. Pulakhton, and P. D. Umarov. 2004. Irrigation systems and their fisheries in the Aral Sea Basin, central Asia. Pages 223-242 in R. Welcomme and T. Petr', editors. Proceedings of the Second International Symposium on the Management of Large Rivers for Fisheries Volume II. RAP Publication 2004/17. FAO Regional Office for Asia and the Pacific, Bangkok, Thailand.

Pigram, J. J. 2000. Viewpoint. Options for rehabilitation of Australia's Snowy River: an economic perspective. Regulated Rivers: Research and Management 16:363-373.

Poff, N. L. 1996. A hydrogeography of unregulated streams in the United States and an examination of scale-dependence in some hydrological descriptors. Freshwater Biology 36:71-91.

Poff, N. L., J. D. Allan, M. B. Bain, J. R. Karr, K. L. Prestegaard, B. D. Richter, R. E. Sparks, and J. C. Stromberg. 1997. The natural flow regime: a paradigm for river conservation and restoration. BioScience 47:769-784.

Poff, N. L., J. D. Allan, M. A. Palmer, D. D. Hart, B. D. Richter, A. H. Arthington, K. H. Rogers, J. L. Meyer, and J. A. Stanford. 2003. River flows and water wars: emerging science for environmental decision making. Frontiers in Ecology and the Environment 1:298-306.
Poff, N. L., J. D. Olden, D. M. Pepin, and B. P. Bledsoe. 2006. Placing global streamflow variability in geographic and geomorphic contexts. River Research and Applications 22: 149-166.

Poff, N. L., and J. V. Ward. 1989. Implications of streamflow variability and predictability for lotic community structure: a regional analysis of stream flow patterns. Canadian Journal of Fisheries and Aquatic Sciences 46:1805-1818.

Postel, S., and B. D. Richter. 2003. Rivers for life: managing water for people and nature. Island Press, Washington, D.C., USA.

Puckridge, J. T., F. Sheldon, K. F. Walker, and A. J. Boulton. 1998. Flow variability and the ecology of large rivers. Marine and Freshwater Research 49:55-72.

Pusey, B. J., M. J. Kennard, and A. H. Arthington. 2000. Discharge variability and the development of predictive models relating stream fish assemblage structure to habitat in north-eastern Australia. Ecology of Freshwater Fishes 9:30 50

Richter, B. D., J. V. Baumgartner, J. Powell, and D. P. Braun. 1996. A method for assessing hydrologic alteration within ecosystems. Conservation Biology 10:1-12.

Richter, B. D., R. Matthews, D. L. Harrison, and R. Wigington. 2003. Ecologically sustainable water management: managing river flows for river integrity. Ecological Applications 13:206-224.

Richter, B. D., A. T. Warner, J. L. Meyer, and K. Lutz. 2006. A collaborative and adaptive process for developing environmental flow recommendations. River Research and Applications 22:297-318.

Rosenberg, D. M., P. McCully, and C. M. Pringle. 2000. Global-scale environmental effects of hydrological alterations: introduction. BioScience 50:746-751.

Rubin, D. M., D. J. Topping, J. C. Schmidt, J. Hazel, M. Kaplinski, and T. S. Melis. 2002. Recent sediment studies refute Glen Canyon Dam hypothesis. Eos 83:273-278.

Sanborn, S. C., and B. P. Bledsoe. 2005. Predicting streamflow regime metrics for ungauged streams in Colorado, Washington, and Oregon. Journal of Hydrology, in press.

Siebentritt, M. A., G. G. Ganf, and K. F. Walker. 2004. Effects of an enhanced flood on riparian plants of the River Murray, South Australia. River Research and Applications 20:765774 .

Smakhtin, V., C. Revenga, and P. Döll. 2004. A pilot global assessment of environmental water requirements and scarcity. Water International 29:307-317.

Snelder, T. H., B. J. F. Biggs, and R. A. Woods. 2005. Improved eco-hydrological classification of rivers. River Research and Applications 21:609-628.

Tharme, R. E. 2003. A global perspective on environmental flow assessment: emerging trends in the development and application of environmental flow methodologies for rivers. River Research and Applications 19:397-442.

Vörösmarty, C., et al. 2004. Humans transforming the global water system. EOS, American Geophysical Union Transactions 85:509-514.

Welcomme, R. L. 2001. Inland fisheries ecology and management. Fishing News Books, Blackwell Science, Oxford, UK. 